\title{
Cortes estratigráficos en la crítica y en la obra de Roberto Bolaño*
}

\author{
Stratigraphic samples in the critique \\ and work of Roberto Bolaño
}

\section{Alejandra Oyarce Orrego}

Universidad de Concepción. Concepción, Chile

alejandraoyarce@udec.cl

\section{RESUMEN}

En este artículo, mediante cortes estratigráficos, a través de una revisión crítica acotada y desde la estética figural de Jean-François Lyotard, reiteramos la inclusión de la figura y de la obra de Roberto Bolaño en la literatura chilena, relacionando Los detectives salvajes con La nueva novela de Juan Luis Martínez.

Palabras clave: Tradición literaria chilena, Roberto Bolaño, Juan Luis Martínez, figuraimagen, pulsión de muerte.

\section{ABSTRACT}

In this article, using stratigraphic samples, through a critical review and specific revision and from the figural aesthetic of Jean-François Lyotard we reiterate the inclusion of the figure and of the work of Roberto Bolaño in the chilean literature, linking Los detectives salvajes with La nueva novela by Juan Luis Martínez.

Keywords: Chilean literary tradition, Roberto Bolaño, Juan Luis Martínez, figureimage, death drive.

Recibido: 06.01.2012. Aceptado: 23.03.2012

* Este artículo forma parte de la tesis de Doctorado en Literatura Latinoamericana (Universidad de Concepción, Chile), en desarrollo, "Los detectives salvajes: la nueva novela de Roberto Bolaño. Narrativa terminal y de continuidad”, financiada y apoyada por la Comisión Nacional de Investigación Científica y Tecnológica, Conicyt. 
T a inscripción de la obra de Roberto Bolaño en la tradición literaria chilena es un problema que la crítica periodística y, en menor medida, la crítica académica no termina de resolver. Así, en este trabajo, nos hacemos cargo de este problema abierto y postulamos la evidencia de esta inclusión, a través de la técnica de cortes estratigráficos ${ }^{1}$, en la crítica sobre Bolaño y en su obra; asimismo, la utilizamos en la dimensión teórica, pues nos basamos en conceptos específicos de la estética figural postfreudiana y postlacaniana que Jean-François Lyotard desarrolla, principalmente, en Discurso, Figura (1979), apoyándonos en el estudio totalizador que Alberto Gualandi realiza sobre su pensamiento teórico en Lyotard (2009), para demostrar a un nivel más profundo nuestra hipótesis. De este modo, pensamos que ante la exponencial cantidad de información crítica sobre la compleja obra de Roberto Bolaño, una mirada acotada, objetiva y en profundidad, contribuiría al objetivo que nos proponemos.

Nuestro primer corte estratigráfico, sobre un segmento específico de la crítica literaria nacional, permite observar que entre la crítica literaria chilena y la obra de Roberto Bolaño existe una relación problemática que proviene de larga data. Esto se visualiza al reactualizar una pregunta que Alberto Fuguet plantea en su trabajo "21 notas sobre la nueva narrativa", que forma parte de Nueva narrativa chilena (1997) y surge del seminario realizado en nuestro país para abordar críticamente la situación de la narrativa hacia fines del siglo $\mathrm{XX}^{2}$ :

Nosotros sí, ustedes no. Por un extraño mecanismo, la Nueva Narrativa incluye a algunos y deja fuera gente clave. Aunque la aldea global lleva ya una década de unión, aquí se sigue pensando como aldea. Es un movimiento que no cree en el fax, le teme a Federal Express, no sabe usar el correo elec-

${ }^{1}$ Tomamos el concepto de corte estratigráfico del trabajo que Michel Houellebecq actualiza en uno de los fragmentos recogidos en su libro Intervenciones (2011), donde reflexiona críticamente en relación al sujeto, al escritor y a la obra de Alain Robbe-Grillet. Aquí explica, en términos técnicos, en qué consiste este procedimiento de la geología que, aplicado a la agronomía y extrapolado a la literatura, funciona para entender y sintetizar la escritura de Robbe-Grillet: "¿Y, una vez cavada la zanja, qué hacemos? Pues observamos. Es decir, que dibujamos con la mayor precisión posible lo que vemos (...). Así, a través del corte estratigráfico, el estudiante de agronomía se forma en esta austera disciplina consistente en considerar el mundo con una mirada neutra y puramente objetiva. ¿Y no es esto lo que Alain Robbe-Grillet intentó hacer más adelante en literatura? (Houellebecq, 2011: 225-256).

${ }^{2}$ El trabajo Nueva narrativa chilena (1997), editado por Carlos Olivárez, se compone de 27 trabajos de críticos y escritores nacionales, que permiten captar la visión de los narradores y de la crítica literaria chilena, académica y periodística que, a fines de los años noventa, analiza y discute en torno a la situación de la narrativa chilena. 
trónico. Skármeta está fuera por edad y fecha de publicación. Sepúlveda, Allende y Dorfman, por ser famosos y vivir fuera, quedan out. ¿Qué pasa con Bolaño, el mejor de todos? (...) (Fuguet, 1997: 122).

Con este cuestionamiento, Fuguet abre un debate que queda en suspenso, pero que permite apreciar el mecanismo de selección y omisión/exclusión con que operaría la crítica literaria chilena y que parece afectar la aproximación de una parte de la crítica a la obra de Roberto Bolaño.

Más recientemente, a propósito del Bicentenario, Ignacio Valente entrega una síntesis titulada "200 años de Literatura chilena", en el suplemento "Artes y Letras" de El Mercurio del 19 de septiembre del 2010. En ella, el crítico nacional opta también por no incorporar a Roberto Bolaño dentro de su revisión de la tradición literaria chilena por considerarlo demasiado reciente. Señala que es prematuro inscribirlo en la tradición y explícitamente manifiesta que es mejor dejar en manos del tiempo esta tarea: "el tiempo, el juez más seguro, deberá decantarlo" (Valente, 2010: E2).

Asimismo, notamos que Camilo Marks, en distintos momentos y trabajos opta por omitir a Bolaño, cuestionando la posibilidad de su inclusión en la tradición literaria chilena. En su intervención en el seminario sobre narrativa antes citado "El nombre no es lo de menos" (Olivárez, 1997: 1520) percibimos que no incluye nombres y, por lo tanto, Bolaño no aparece mencionado. Seis años más tarde, en "Roberto Bolaño el esplendor narrativo finisecular" que forma parte de Territorios en fuga de Patricia Espinosa (2003), lo incorpora, pero en términos generales, como un destacado narrador contemporáneo, un novelista sin parangón, acaso el autor más destacado de la actualidad, pero que "no pertenece a la historia de la literatura chilena" (Espinosa, 2003: 126). Posteriormente, en su publicación más reciente, Canon. Cenizas y diamantes de la narrativa chilena (2010), entrega una amplia revisión de la tradición literaria. En esta oportunidad, se refiere a la obra de Bolaño abordándola como una producción literaria llamativa y original, reitera la idea de considerar al autor como un importante escritor contemporáneo. No obstante, notamos que la distancia instalada entre su obra y la literatura chilena se mantiene, confirmando la visión excluyente que predomina en un sector de la crítica chilena. Así lo advertimos, de manera más específica, en el capítulo titulado "Roberto Bolaño, gloria póstuma”, en el que Marks, categóricamente niega cualquier posibilidad de vincular al escritor con nuestro país, con la literatura chilena y la tradición novelística nacional, tal como se observa en el siguiente párrafo: 
¿Qué quiere decir todo esto? Muy poco, salvo que, de modo categórico, Roberto Bolaño no es, en esencia, un escritor chileno. Se encuentra por completo al margen de la literatura chilena y es imposible asociarlo con la tradición novelística de este país (Marks, 2010: 199).

Además, a pesar de desplegar una serie de elogios y de confirmar que en varias obras de Bolaño la acción remite a Chile y que en algunas de sus destacadas novelas, como Estrella distante (1996) y Nocturno de Chile (2000), el escritor aborda temas complejos, relacionados con nuestro país y su pasado inmediato, Marks continúa negando la posibilidad de pertenencia del narrador a nuestra tradición literaria. Nuevamente, sin aportar argumentos críticos ni teóricos que sustenten su posición.

La tendencia crítica anterior se opone al amplio interés investigativo que gran parte de la crítica especializada ha realizado de la obra bolañeana y que ha ido aumentando progresivamente, insistiendo en la idea de reafirmar a Roberto Bolaño como escritor chileno fundamental para la literatura contemporánea. Efectivamente, en nuestra revisión encontramos una serie de publicaciones y estudios críticos que aportan una serie de elementos relevantes al análisis general y que, principalmente, coinciden en enfatizar la importancia del escritor, su excepcional talento, originalidad y complejidad de su obra. Así ocurre con publicaciones como: Territorios en fuga de Patricia Espinosa (2003) y Roberto Bolaño. La escritura como tauromaquia de Celina Manzoni (2006), ambos trabajos recogen los primeros acercamientos críticos a la obra de Roberto Bolaño. Luego, Bolaño salvaje de Edmundo Paz Soldán y Gustavo Faverón Patriau (2008), que reúne una serie de aproximaciones de diversos autores y permite constatar el interés creciente hacia la obra. Posteriormente, Pistas de un naufragio. Cartografía de Roberto Bolaño de Chiara Bolognese (2009) y Bolaño otra vuelta de tuerca de Patricia Poblete Alday (2010), presentan una tendencia hacia la profundidad en el análisis crítico. También se destaca Bolaño Infra. 1975-1977. Los años que inspiraron Los detectives salvajes (2010) de Montserrat Madariaga Caro, una exploración que incluye entrevistas y recopilación de testimonios con el fin de reconstruir la biografía. De manera más reciente, El héroe improbable, de Sergio Marras (2011), expone una mirada profunda y acotada de la obra bolañeana. Los trabajos mencionados se relacionan entre sí, pues además de poner énfasis en la importancia del escritor, reiteran la necesidad de continuar estudiando la obra, pues se ha insistido en abordar a Bolaño desde el concepto de "oveja negra”, autor de un proyecto literario único, ajeno a la literatura chilena.

$\mathrm{Al}$ continuar la indagación, observamos que existen puntos de vista bas- 
tante críticos en relación a la forma en que se ha leído y criticado la obra bolañeana, es el caso de Alejandro Zambra. En varios de sus trabajos, Zambra deja manifiesta su contrariedad frente a la crítica que clasifica y excluye sin terminar de comprender el proyecto literario. Destacamos su lectura del poemario Tres (2000), en su ensayo "La montaña rusa" que forma parte de Roberto Bolaño. La escritura como tauromaquia. En este trabajo, expone su visión de la obra bolañeana, resaltando la forma restringida y sesgada con la que mayoritariamente se ha leído y criticado hasta ese momento, por lo que recalca la necesidad de estudiar y entender, en profundidad, el proyecto literario de Bolaño.

En un sentido similar, notamos que la perspectiva descrita anteriormente se conecta con las ideas abordadas por Ignacio Echevarría, quien percibe y enfatiza la relación entre Roberto Bolaño y Nicanor Parra. El crítico español destaca la filiación con el antipoeta, reafirmándolo como un precursor fundamental, puesto que la obra de Bolaño, a todas luces, se conecta íntimamente con la obra parriana. Este antecedente surge en contraposición a la visión excluyente descrita antes, al evidenciar que hay una innegable vinculación entre Bolaño y la literatura chilena, en la medida en que la obra bolañeana despliega una relectura de la obra de Parra. Esta idea se concentra y refuerza en las palabras de Bolaño en "Ocho segundos con Nicanor Parra", incluido en Entre paréntesis (2008 [2004]):

El que sea valiente que siga a Parra. Sólo los jóvenes son valientes, sólo los jóvenes tienen el espíritu puro entre los puros. Pero Parra no escribe una poesía juvenil. Parra no escribe sobre la pureza. Sobre el dolor y la soledad sí que escribe; sobre los desafíos inútiles y necesarios; sobre las palabras condenadas a disgregarse así como también la tribu está condenada a disgregarse. Parra escribe como si al día siguiente fuera a ser electrocutado. El poeta mexicano Mario Santiago, hasta donde sé fue el único que hizo una lectura lúcida de su obra. Los demás sólo hemos visto un meteorito oscuro. Primer requisito de una obra maestra: pasar inadvertida (Bolaño, 2008 [2004]: 92).

Constatamos que, a lo largo de su proyecto literario, Bolaño muestra una marcada admiración por la obra parriana; en forma explícita, señala en varios de sus escritos que el trabajo de Nicanor Parra es de enorme importancia para la literatura nacional, por lo que pervivirá en este siglo, pues se proyecta hacia el futuro y contribuye a la literatura nacional, renovándola. Al mismo tiempo, Bolaño comparte con el antipoeta algunas problemáticas 
centrales, como ocurre, por ejemplo, con la irónica crítica desarrollada en relación al mundo literario y la crítica chilena. Específicamente, destaca que en uno de los antipoemas, Parra logra resumir en tres versos toda la historia de la literatura nacional, rescatando la forma creativa en que, con un artefacto explosivo, el antipoeta zanja el debate que, a juicio de ambos, ha reinado en la crítica que adolece de una lamentable arbitrariedad en sus juicios y de un nacionalismo nefasto, pues equivocada y sistemáticamente, intenta establecer para siempre el nombre de los mejores poetas de Chile, proceso en el que obligatoriamente alguien sobra y debe quedar fuera, pues siempre son cuatro las sillas y cinco los poetas:

\section{Los cuatro grandes poetas de Chile son tres \\ Alonso de Ercilla y Rubén Darío}

(Bolaño, 2008 [2004]: 44).

En un sentido similar, encontramos que en Nicanor Parra hay un reconocimiento hacia la figura de Roberto Bolaño, a quien se le atribuye un protagonismo decisivo en el impulso que posibilita la publicación de sus Obras Completas \& algo +, el año 2006. Así lo confirman los editores, Ignacio Echevarría y Niall Binns, en la presentación del primer tomo publicado en 2006, en el apartado Agradecimientos'

La insistencia de Bolaño, ferviente admirador de Parra -a quien tenía por uno de sus maestros-, influyó sin duda en que el antipoeta consintiera finalmente, y en que lo hiciera dando muestras de una confianza y de una generosidad que han sido altamente estimulantes (Parra, 2006: 22).

En consecuencia y observando detenidamente el contexto en el que hemos desplegado nuestro corte, notamos que la dificultad que implica abordar la obra de Bolaño en relación a la literatura chilena se produce por varias razones, que sintetizamos a continuación.

En primer lugar, porque innegablemente Bolaño desarrolla su proyecto literario principalmente fuera de Chile, distancia que induce a la exclusión $\mathrm{o}$, al menos, promueve mantenerlo al margen. Lo que puede captarse en las

${ }^{3}$ Esta idea es reiterada y amplificada recientemente por el antipoeta y por la crítica que, a propósito de la noticia del Premio Cervantes 2011, destaca y valora el fervoroso rescate que Bolaño realiza de su nombre y de su obra. 
palabras de Camilo Marks:

En realidad Bolaño podría ser mexicano, español, chicano y en parte chileno o, a lo mejor, una mezcla de todas esas nacionalidades pero, en definitiva, está al margen de la literatura chilena reciente (Marks, 2010: 199).

En segundo lugar, porque la figura de Bolaño resulta compleja para la crítica chilena, esto se comprende al revisar el duro cuestionamiento que el escritor desarrolla en relación al mundo literario nacional y, sobre todo, la visión crítica que manifiesta en relación a los procedimientos arbitrarios y excluyentes que, a su juicio, predominan en nuestro país a la hora de construir el canon, ideas que despliega notoriamente a lo largo de su obra literaria y que puede ser captada en el siguiente fragmento del texto "La literatura chilena" recogido en Entre paréntesis:

Esto es lo que aprendí de la literatura chilena. Nada pidas que nada se te dará. No te enfermes que nadie te ayudará. No pidas entrar en ninguna antología que tu nombre siempre se ocultará. No luches que siempre serás vencido. No le des la espalda al poder porque el poder lo es todo. No escatimes halagos a los imbéciles, a los dogmáticos, a los mediocres, si no quieres vivir una temporada en el infierno. La vida sigue aquí más o menos igual (Bolaño, 2008 [2004]: 66).

En tercer lugar, porque se tiende a considerar sólo la escritura narrativa del autor, conocida a partir de la segunda mitad de la década de los noventa, y frecuentemente no se tiene en cuenta la producción poética que involucra más de dos décadas de su carrera como escritor; es decir, duplica el período destinado a la narrativa. Dentro de su trabajo literario total, la etapa destinada a la escritura poética tiende a desestimarse, calificándola incluso como una obra sin mayor valor, ni trascendencia; puesto que, bajo esta lectura, es el fracaso como poeta y el distanciamiento de la poesía lo que posibilitaría la obra narrativa de Bolaño. Esta idea puede captarse, por ejemplo, en palabras de Raúl Zurita, quien en una entrevista que forma parte de la nota titulada "Roberto Bolaño y Raúl Zurita: Referencias cruzadas" (2010) de la investigadora Chiara Bolognese. En ella, el poeta chileno califica como "insufrible" la producción poética de Bolaño y explica que de su pésima calidad poética y de la frustración que ello le produce, surgiría el giro hacia la narrativa, a la que sí reconoce sobrados méritos. Esta visión surge en contraposición a lo expuesto por otros críticos y escritores. Es el caso de Zambra, como se 
advierte también en su trabajo "La montaña rusa" antes mencionado. Aquí, Zambra plantea que la obra de Bolaño no ha sido leída adecuadamente y, en este sentido, destaca la importancia del trabajo poético del autor, reivindicando a Bolaño como poeta y rescatando el carácter libre de su escritura. Aclara que más allá de verso o prosa, Bolaño escribe literatura. Esta visión es desarrollada también en forma posterior, en No leer. Crónicas y ensayos sobre literatura (Zambra, 2010: 100), donde nos recuerda que toda la poesía cabe en una novela y que, para Archimboldi, sólo una novela puede comunicar lo que es la poesía. En este sentido, la conexión narrativa-poesía es clave en el proyecto escritural de Bolaño, ya que en su ejercicio de la literatura no hay una oposición entre géneros, sino más bien una comunicación vital y estructural, que aún no ha sido estudiada del todo.

En cuarto lugar, y en relación con el punto anterior, se tiende a no considerar que poesía, narrativa y ensayo, son dimensiones de la escritura que, en el proyecto literario bolañeano, resultan inseparables. La escritura poética, narrativa y reflexiva, forman parte de un solo proyecto escritural en el que éstas dimensiones están tan imbricadas que no pueden ser pensadas por separado y donde el trabajo crítico desplegado durante su vida es parte fundamental del proyecto literario total. Todo esto contribuye a mostrar, de manera más profunda, los límites de un sector considerable de la crítica chilena que aún funciona guiada por una separación de la obra en géneros literarios, aspecto ampliamente superado por la reflexión teórica contemporánea sobre el lenguaje y la literatura.

Por lo tanto, creemos que la discusión se supera cuando se inscribe a Bolaño en la literatura chilena sin distinguir géneros, y se refuerza en la medida en que se demuestra, en términos objetivos, formales y en dimensiones más profundas, su filiación con la literatura nacional, de manera general, como también, en términos específicos. Lo que, por supuesto, no invalida su condición de escritor latinoamericano con proyecciones universales.

De este modo, aparece el trabajo de Roberto González Echevarría que permite sintetizar, en gran medida, nuestra visión. En su nota "Nocturno de Chile y el Canon" (2010) realiza una rigurosa aproximación al proyecto de Roberto Bolaño, a través de la revisión de una obra particular, trabajo que da cuenta de una profundidad vinculada íntimamente a la idea de cortes estratigráficos. El crítico cubano expone con precisión los criterios de evaluación que guían su observación y análisis, los que se distribuyen en cinco aspectos que dan cuenta de la importancia de Nocturno de Chile (2000). Primero, aborda lo relacionado con lo que él denomina la elevación o altura de la obra, al abordar temas relevantes, como la muerte a la que parece 
abocado el protagonista, sumado a la capacidad de la obra de mostrar su urdimbre literaria. Segundo, la obra logra revelar su contextura literaria, a la vez que asume un tono reflexivo e irónico, porque en ella se desarrolla con gran profundidad la confesión de un sacerdote altamente consciente de la construcción de su discurso, Sebastián Urrutia Lacroix, que es también un crítico literario. Tercero, la obra guarda un secreto, un misterio, un punto ciego para el crítico que, según González Echevarría, tiene que ver con la temática fascista, sugerida por la pertenencia del protagonista al Opus Dei. Cuarto, en Nocturno de Chile se filtra la tradición literaria chilena y universal, destacando en Bolaño la figura de un escritor docto, conocedor a fondo de la literatura y la historia de Chile, como también de la tradición occidental y, bajo esta lectura, en la diatriba contra la política italiana y chilena. Finalmente, el quinto criterio tiene que ver con el estilo o la prosa de la obra que alcanza un alto nivel, al considerar que Bolaño logra expresarse en un grado crítico, culto y elevado, con oportunas alusiones al arte, la filosofía, la historia y la literatura. Notamos, además, que entre las ideas desarrolladas hace énfasis en uno de los puntos que nos parece medular, al reflexionar sobre cómo hacemos juicios de valor literario, en qué principios nos basamos y en qué se apoyan esos principios.

Destacamos que el trabajo de González Echevarría entrega un análisis acotado, a la vez que deja ver con claridad su posición crítica respecto a la figura del escritor, al valor de su obra y a su lugar en la literatura chilena:

El chileno Roberto Bolaño, quien, con trágica disposición para serlo, murió joven, (de 50 años; sus fechas son 1953-2003), es el único narrador latinoamericano reciente cuyos éxitos en nuestro ámbito y el extranjero nos recuerdan los del Boom, y anuncian tal vez la llegada de una nueva era de esplendor... Creo que Nocturno de Chile permanecerá en el canon de la literatura latinoamericana, y el de la occidental. Es una pequeña obra maestra al nivel, y a veces por encima del nivel, de lo mejor que escribieron los novelistas consagrados del canon- los del Boom. Pienso que Bolaño es mejor novelista que José Donoso, para ponerlo en un contexto estrictamente chileno (González Echevarría, 2010: 117) ${ }^{4}$.

\footnotetext{
${ }^{4}$ Además de la nota de González Echevarría, destacamos el libro de Sergio Marras, El héroe improbable (como Arturo Belano siempre quiso ser Benno von Archimboldi) (2011), pues permite mostrar también la idea del corte estratigráfico al presentar una aproximación acotada y profunda de la producción narrativa de Bolaño, a partir de una obra central. Según Marras, Amberes (2002) puede entenderse como el magma iniciático que condensa toda su producción narrativa, un universo contenedor del itinerario bolañeano.
} 
Al seguir con nuestra observación, notamos que la vinculación entre la obra de Roberto Bolaño y la literatura chilena puede hacerse aún más visible al examinar el vínculo literario de la obra bolañeana con el trabajo realizado por algunos poetas chilenos, el que no sólo se agota en la innegable conexión con la figura y obra de Parra, sino que se extiende además a otras propuestas poéticas nacionales.

En esta dirección surge una idea fundamental que respalda esta lectura. $\mathrm{Al}$ reactualizar y confirmar la hipótesis que adelantaba Enrique Lihn, hacia fines de los años setenta del siglo XX, en relación al auge de la novela hispanoamericana en los años sesenta, traducida en el "Boom", en función de la mayor significación de la poesía en comparación con la novela, desde el modernismo hasta la postvanguardia, pasando por la vanguardia, en cuanto percepción del objeto poético como un hecho de lenguaje, intransitivo o, en términos estructuralistas o postestructuralistas, escritura ${ }^{5}$. En otras palabras, pensamos que la idea planteada por Lihn para el boom de la novela hispanoamericana sería aplicable a la novela del postboom y, concretamente, permitiría entender el proceso escritural desplegado en la obra literaria de Roberto Bolaño, al formar parte de una tradición crítica o autorreflexiva en la literatura hispoamericana y, sobre todo, como experiencia límite con el lenguaje, en el caso específico de la poesía chilena, desde Huidobro hasta la actualidad, pasando principalmente, en el caso de la obra bolañeana, por Parra, Lihn, Lira, Martínez; entre otros.

${ }^{5}$ En 1978, en New York, Luis A. Díez realiza una extensa entrevista a Enrique Lihn. En primera instancia, ella fue publicada en los números 1 y 2 de Hispanic Journal en 1980 y 1981; más recientemente fue compilada por Daniel Fuenzalida en Enrique Lihn Entrevistas (2005); en ambos momentos, la entrevista fue dividida en tres partes, con los siguientes títulos: "Enrique Lihn: poeta esclarecedoramente autocrítico", "La narrativa agenérica de Enrique Lihn", "Enrique Lihn: La poética de la reconciliación". Al reflexionar sobre la narrativa experimental de Lihn, éste y Díez intentan buscar una explicación para el éxito de la narrativa del boom en la tradición poética hispanoamericana; particularmente en la vanguardia, en los trabajos narrativos de algunos de sus representantes mayores, como también, en algunas figuras excéntricas de la narrativa hispanoamericana y chilena. En este contexto, Lihn sintetiza: "Sí, creo que es una tesis totalmente legítima. Incluso se podría pensar en términos puramente estructuralistas y rastrear cómo la poesía es, de alguna manera, el antecedente de la nueva novela. $\mathrm{O}$, al menos, de cierto tipo de novela hispanoamericana que viene de la poesía. Es más, podría generarse un tipo de narrativa que no le deba tanto a la poesía en su aspecto formal o de procedimiento, sino que tuviera que ver con la estructura profunda del poema. O sea, que dentro de ella, estaría esta conciencia de ser un instrumento lingüístico. Me refiero a un texto en que la relación del lenguaje con lo real se diera en el mismo lenguaje. Y esto es, después de todo, la motivación primaria del texto poético. Así como la poesía postula la realización de lo real en términos de la palabra, eso mismo podría transferirse al campo de la prosa. Esta conciencia, que es virtual en la poesía, puede radicalizarse en una prosa que no tenga nada de poético en lo formal de los procedimientos, sino en la instancia de apertura hacia lo real en el lenguaje" (Fuenzalida, 2005: 14-15). 
Además, notamos que en la crítica especializada en la obra bolañeana existe cierto consenso en que el proyecto literario bolañeano, pese a que se ha destacado sistemáticamente más en su vertiente narrativa, tendría su núcleo en la poesía. En este contexto, proponemos un segundo corte estratigráfico que nos permite entrar en la producción narrativa de Bolaño y llevar a cabo un acercamiento acotado. En este caso, el corte lo realizamos en Los detectives salvajes $(1998)^{6}$, pues recoge una serie de personajes, temas y procedimientos que condensan el proyecto literario del autor, transformándola en núcleo de su propuesta narrativa.

$\mathrm{Al}$ revisar la obra narrativa, reaparecen los versos en los que se encuentra el embrión de su narrativa, como sucede con Los detectives salvajes (LDS). Esta idea es abordada por Matías Ayala en "Notas sobre la poesía de Roberto Bolaño" que forma parte de Bolaño salvaje (2008). En él se traza una lectura que plantea la posibilidad de un análisis centrado en el diálogo entre narrativa y poesía, enfatizando que los poemas de Bolaño pueden convertirse en un registro que permitiría investigar retrospectivamente su proceso creativo. Podemos comprobar la hipótesis de Ayala, por ejemplo, al examinar el poema "Sión":

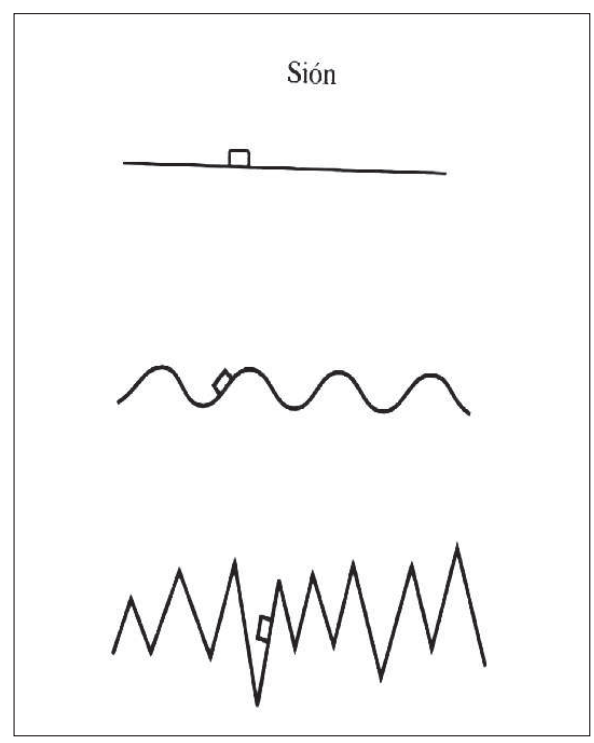

(Bolaño, 2007 [1998]: 376).

El poema-imagen anterior forma parte de $L D S$ y, en una revisión bibliográfica de la obra del autor, se detecta que su embrión se encuentra en la poesía anterior de Bolaño, específicamente, en el texto "El mar", que es re-

${ }^{6}$ De ahora en adelante, abreviamos el título como $L D S$. 
cogido en Amberes (2002: 53) y en La universidad desconocida (2007: 204), con leves variaciones:

\section{EL MAR}

"Fotos de la playa de Castelldefels... Fotos del camping... El mar contaminado... Mediterráneo, octubre en Cataluña... Solo... El ojo de la Zenith...
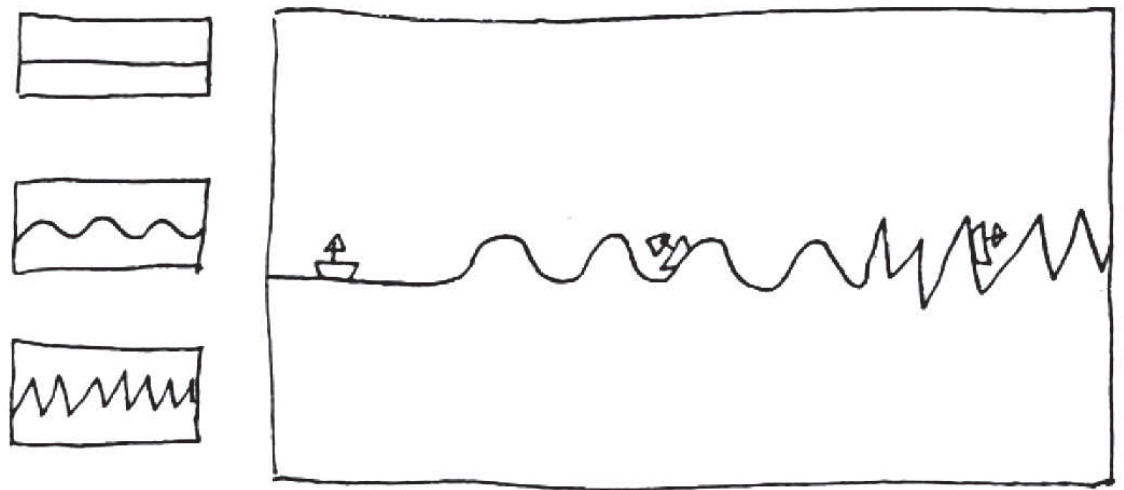

La ondulada me inquietaba, presentía el peligro pero me gustaba la suavidad: subir y bajar. La última línea era la crispación. Me dolía el pene, el vientre, etc.".

(Bolaño 2002: 53).

\section{EL MAR}

"Fotos de la playa de Castelldefels... Fotos del camping... El mar contaminado... Mediterráneo, septiembre en Cataluña... Solo... El ojo de la Zeníth...

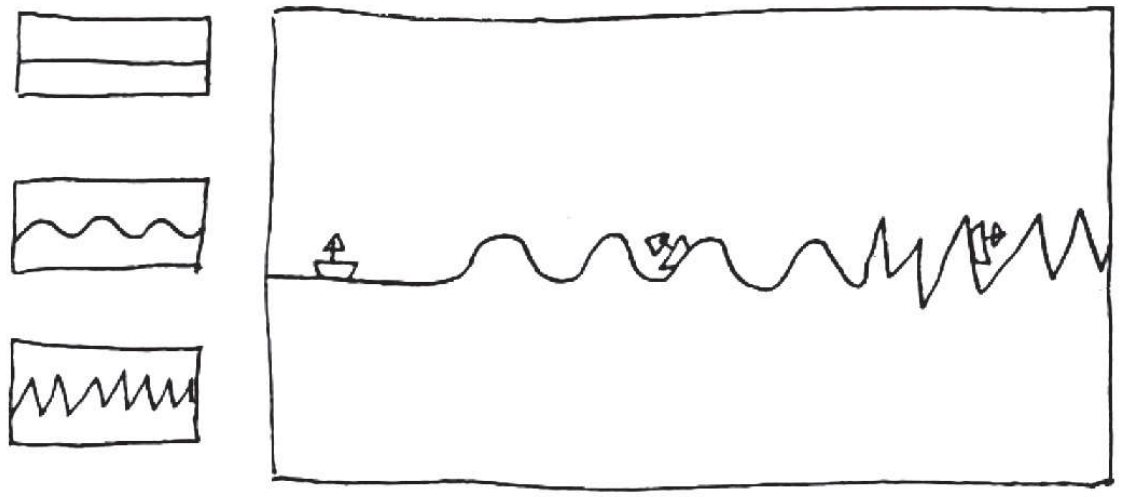

La línea recta me producía calma. La línea curva me inquietaba, presentía el peligro pero me gustaba la suavidad: subir y bajar. La última línea era la crispación. Me dolía el pene, el vientre, etc."

(Bolaño 2007: 204). 
El movimiento hacia el cual tiende la obra de Bolaño en su proyecto literario está marcado por una revitalización de la literatura, desde la línea recta, la calma o la inmovilidad, seguida de un movimiento ondulatorio que conduce a la crispación final.

Notamos que, con $L D S$, el autor asume el desafío de renovar la narrativa, para lo cual busca una nueva forma para la novela y asume el riesgo de presentarse como una obra fuera de la tradición, a través de un proyecto escritural complejo que implica un quiebre con la narrativa tradicional. En consecuencia, podemos confirmar que la propuesta de Bolaño se aleja de la tradición narrativa chilena, pues su proyecto escritural no está pensado en relación a la tradición novelística, aunque no se aleja de la literatura chilena, dado que se relaciona con algunos de los proyectos poéticos más relevantes de nuestra literatura. Esto, se observa a raíz de la conexión que se produce entre $L D S$ y el proyecto literario terminal de Juan Luis Martínez, específicamente La nueva novela $(1977)^{7}$, uno de los textos más enigmáticos de la literatura chilena. La crítica reconoce que el trabajo de Martínez se caracteriza por la búsqueda de una nueva forma para la poesía, así también, proponemos el trabajo de Bolaño cómo búsqueda de una nueva forma para la novela, abriendo nuevos espacios de creación y reflexión, que lo vincularían con la tradición poética chilena.

Observamos que la crítica a $L N N$, coincide en calificarla como una obra compleja que marca un quiebre en la literatura nacional y rompe con todas las formas tradicionales de la poesía en Chile. La obra cuenta con un considerable número de trabajos que intentan dar cuenta de un proyecto literario singular, misterioso y prácticamente indescriptible, por sus características particulares. Entre los primeros acercamientos críticos encontramos: "Juan Luis Martínez, La nueva novela" de Enrique Lihn (1985), compilado más tarde en El circo en llamas (1997). Luego, Señales de ruta de Enrique Lihn y Pedro Lastra (1987), quienes la describen y califican como un libro inabordable para las empresas editoriales chilenas y para la crítica, al presenciar la desaparición del autor en un sujeto cero que materializa un proyecto literario que tiene mucho de utópico al intentar escapar de la temporalidad. Más tarde, "Juan Luis Martínez: La nueva novela. La memoria secreta”, de Roberto Merino (1988), en que destaca el carácter secreto, oculto en la obra, bajo la transparencia de su superficie. Posteriormente, "La subversión lógica de Juan Luis", de Jaime Valdivieso (1996), en que destaca que la obra

${ }^{7}$ De ahora en adelante, abreviamos el título como $L N N$ y citamos de la primera edición de 1977. 
de Martínez es un desafío permanente a la forma tradicional de pensar y ver la realidad. Luego, "La acción innovadora de Juan Luis Martínez" de Manuel Espinoza Orellana (1998), en que se destaca el carácter rupturista y las inagotables posibilidades de lectura de $L N N$ en la medida que entraña la permanente búsqueda de las posibilidades del signo. En el mismo año, Juan Luis Martínez. El juego de las contradicciones, de Patricia Monarca (1998), sintetiza el estado de la crítica hasta ese momento e insiste en la necesidad de un estudio en profundidad de esta obra enigmática y comunica la posibilidad de abordarla desde la idea del juego de contradicciones y la presencia de la "lógica absurda" que recorre la obra de principio a fin. Posteriormente, "La nueva novela de Juan Luis Martínez: Poesía protohipertextual en el contexto de la videósfera” de Juan Herrera (2007), cuya lectura está propuesta desde la idea de la irrupción y la centralidad de la imagen, sobre la escritura, en sentido superficial y profundo, hecho que determina la importancia de la obra martiniana en el contexto de la poesía chilena de los años ochenta. Más tarde, Felipe Cussen aborda la obra y su ideal de transparencia, en un diálogo desde la música, en "Del pajarístico al lenguaje de los pájaros" (2009). Posteriormente, Pedro Lastra realiza una síntesis de la obra y la reactualiza, destacando su importancia y enfatizando que la crítica oficial, en términos generales, no termina de entender un proyecto tan complejo como el de Juan Luis Martínez, todo ello en su trabajo "Marginalidad y poesía en Hispanoamérica" en Chile mira a sus poetas, año 2011. Finalmente, Patricia Monarca publica en 2011 un libro decisivo para el estudio de LNN: Mutación Epistémica. (Una lectura de La Nueva Novela desde la interdisciplinariedady la complejidad del saber), cuya perspectiva está explícita en el subtítulo de su trabajo y, junto con actualizar y afinar la bibliografía sobre la obra, incluye una útil linkografía.

Con este paréntesis bibliográfico sobre el proyecto martiniano es posible observar y revisar el vínculo entre $L D S$ y $L N N$. Tomamos como punto de partida que en ambos textos se presenta una idea dominante, se trata de considerar la obra literaria como investigación, como producción. Conscientes de que su ejercicio literario encierra la peligrosa búsqueda de una forma, para la poesía, en el caso de Martínez y para la novela, en el caso de Bolaño. En este sentido, observamos que $L D S$ es un texto que concentra mucha información y permite condensar el proyecto literario del autor, lo que también ocurre en el caso de la $L N N$. Conciente de que la poesía ya no es posible luego del trabajo literario de Juan Luis Martínez, Bolaño opta por una escritura narrativa compleja, sin abandonar las reflexiones y procedimientos de su escritura poética. En consecuencia, surgiría la posibilidad 
de entender el proyecto literario desplegado en $L D S$ bajo el concepto martiniano de nueva novela.

De esta manera, luego de mostrar el resultado de los cortes estratigráficos en la crítica literaria y en la obra de Roberto Bolaño, pasamos a exponer los resultados de nuestro tercer corte estratigráfico, en este caso, sobre la teoría, pues esta dimensión nos permite unir los aspectos anteriores. Hemos escogido la estética figural de Jean-François Lyotard, pues sería la base teórica que nos permitiría relacionar en un nivel más profundo $L D S$ y $L N N$. Es el caso de la incorporación de figuras-imágenes y jeroglíficos como parte de la escritura en $L D S$ y $L N N$, lo que puede ser abordado como un desafío límite al uso del lenguaje. Se trata de proponer enigmas, que suponen la búsqueda de soluciones y su finalidad se entiende, siguiendo a Lyotard en Discurso, Figura (1979), en la producción de "homófonos salvajes" "que resultan de un desplazamiento sobre el significante fónico y, en ocasiones, puede incluso devenir en chistes que conllevan un desplazamiento sobre el significado. En este contexto se comprende la incorporación de una serie de figurasimágenes que aparecen como parte de un juego y que consiste en descifrar ciertas imágenes o acertijos:

Me puse a hacer dibujos que son enigmas que me enseñaron en la escuela hace siglos. Aunque aquí no hay charros....-¿Qué es esto dije?

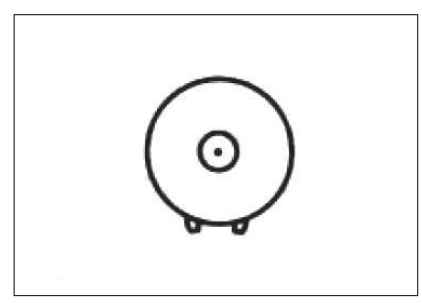

Lupe miró el dibujo como si no tuviera ganas de jugar y se quedó callada. Belano y Lima tampoco lo sabían. -¿Un verso elegíaco?- dijo Lima. -No. Un mexicano visto desde arriba-dije-¿y esto? (Bolaño, 2007 [1998]: 574).

Este juego de preguntas a través de acertijos construidos de imágenes, continúa por largo rato, en el transcurso de la parte final del viaje de búsqueda de Cesárea Tinajero. La risa se apodera de la escena con la interpretación de los dibujos: un mexicano fumando pipa, un mexicano en bicicleta, un mexicano friendo un huevo... Hasta que aparece la última pregunta " $¿ Y$

\footnotetext{
${ }^{8}$ El concepto de homófonos salvajes, explicado por Lyotard en Discurso, Figura, propone como un aspecto central de la reflexión la idea de figura, como una revalorización en el arte de aquellos elementos irreductibles a la significación, y en ese contexto se aborda el concepto de jeroglífico.
} 
esto?, seguido de la siguiente imagen:

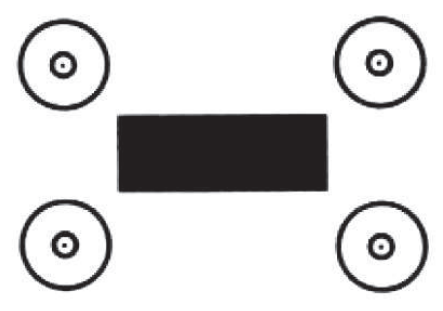

Cuatro mexicanos velando un cadáver, -dijo Belano” (Bolaño, 2007 [1998]: 577).

En este mismo sentido, situamos la figura-imagen final de LDS:

15 de febrero

¿Qué hay detrás de la ventana?

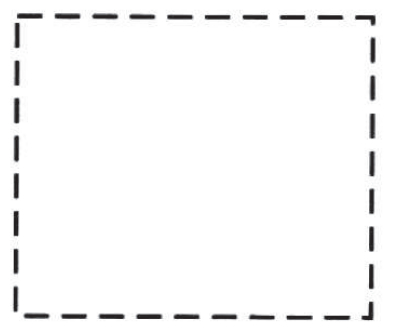

(Bolaño, 2007 [1998]: 609).

La instalación del enigma se conecta con uno de los acertijos contenidos en La nueva novela de Martínez, específicamente en el texto "La casa del aliento. Casi la pequeña casa del autor", que es también una apelación y un desafío al lector: 
"LA CASA DEL ALIENTO, *

CASI LA PEQUEÑA CASA DEL(AUTOR)

\author{
a Isabel Holger Dabadie \\ a Luis Martínez Villablanca
}

(Interrogar a las ventanas

sobre la absoluta transparencia

de los vidrios que faltan)".

a) La casa que construiremos mañana ya está en el pasado y no existe.

b) En esa casa que aún no conocemos sigue abierta la ventana que olvidamos cerrar.

c) En esa misma casa, detrás de esa misma ventana Se baten todavía las cortinas que ya descolgamos.

* "Quizás una casita en las afueras donde el pasado tiene aún que acontecer y el futuro hace tiempo que pasó”

(De T.S.Eliot, casi).

(Martínez, 1977: 90).

En un nivel más profundo, notamos la importancia que adquiere el desierto en este proceso de desaparición de tiempo y espacio, y nos conecta con una dimensión que, una vez más, une los proyectos literarios de Bolaño y Martínez. En $L D S$, la búsqueda conduce al desierto, a la desaparición y la muerte. Esta idea reaparece en otro texto de $L N N$ : 


\section{"NOTA 1. LA DESAPARICIÓN DE UNA FAMILIA}

Véase: EPIGRAFE PARA UN LIBRO CONDENADO*

"La casa que construirás mañana, ya está en el pasado y no existe"

Anónimo

"El hombre nace en la casa, pero muere en el desierto"

Proverbio del Gran Lama Errante,

Oído por S.-J. Perse en el desierto de Gobi.

(Martínez, 1977: 121).

Luego, apreciamos que en $L D S$ se presenta un jeroglífico que funciona como enigma central, se trata del poema-visual de Cesárea, "Sión", antes incluido. En el intento por abordar el mítico poema, a través del juego que Belano, Lima y García Madero desarrollan, se observa lo siguiente:

"Ahora vamos con el primer corte del poema ¿qué tenemos? Una línea recta y sobre ésta un rectángulo, dije. Bueno, dijo el chileno, olvídate del rectángulo, has de cuenta que no existe. Mira sólo la línea recta. ¿Qué ves? Una línea recta dije. ¿Qué otra cosa podría ver, muchachos? ¿Y qué te sugiere la línea recta, Amadeo? El horizonte, dije. El horizonte de una mesa, dije. ¿Tranquilidad?, dijo uno de ellos. Sí, tranquilidad, calma. Bien: horizonte y calma. Ahora veamos el segundo corte del poema: ¿Qué ves Amadeo? [...] ¿Qué te sugiere la línea ondulada? ¿Una premonición de la calma que se altera? [...] ¿'Movimiento, ruptura?” (Bolaño, 2007 [1998]: 399).

Este enigma que desafía al lector puede conectarse también con $L N N$, específicamente con el texto "Tareas de poesía": 


\section{Tareas de poesía}

Tristuraban las agras sus tenorios

Los lirosos durfían tiestamente

Y ustiales que utilaban afimorios

A las folces turaban diestamente.

Hoy que dulgen y ermedan los larorios

Las oveñas patizan el bramente

Y las fólgicas barlan los filorios

Tras la Urla que valiñan ristramente.

\section{EXPLIQUE Y COMENTE:}

1. ¿Cuál es el tema o motivo central de este poema?

2. ¿Qué significan los lirosos para el autor?

3. ¿Por qué el autor afirma que las oveñas patizan el bramente?

4. ¿Qué recursos expresivos encuentra en estos versos?

"y las fólgicas barlan los filorios

Tras la Urla que valiñan ristramente".

5. Ubique todas aquellas palabras que produzcan la sensación de claridad, transparencia.

6. ¿Este poema le produce la sensación de quietud o de agitado movimiento? Fundamente su respuesta.

(Martínez, 1977: 95).

En el capítulo II de su estudio sobre Lyotard, "Le dehors du langage", Gualandi sintetiza críticamente el proyecto y los conceptos teóricos de J. F. Lyotard en relación al arte y a la literatura, los cuales veríamos funcionando en el trabajo creativo de ambos escritores chilenos, en cuanto artistas postmodernos; es decir, en su búsqueda de una forma para la poesía y para la narrativa a través de sus obras autorreflexivas y complejas al extremo? ${ }^{9}$. Esto

9 Según Lyotard, en el apartado "Lo posmoderno" de La posmodernidad (explicada a los niños): "un artista, un escritor posmoderno, están en la situación de un filósofo: el texto que escriben, la obra que llevan acabo, en principio, no están gobernados por reglas ya establecidas, y no pueden ser juzgados por medio de un juicio determinante, por la aplicación a este texto, a esta obra, de categorías conocidas. Estas reglas y estas categorías son lo que la obra o el texto investigan. El artista y el escritor trabajan sin reglas y para establecer las reglas de aquello que habrá sido hecho" (Lyotard, 2008: 25). 
se vincula con lo que señala Gualandi en su lectura de Lyotard:

Lorsque le non-dit se montre dans le discours, ce qui se produit c'est la figure, et là où la "vérité figurale" apparaît dans le discours avec la force d'un evénement qui le fracture, là, soutient Lyotard, il y a l'art. Lárt n'est pas l'expressión d'une vérité qui attend le sceau d'un discours de savoir pour pouvoir se dire en tant que telle. Bien au contraire! La vérité de l'art ne se produit qu'en transgression des règles qui ordonnent le discours en système et qui définissent vis-à-vis du discours un espace de perception où prend corps une réalité stable. L'art est production, affirme Lyotard, mais le travail qu'il accompli test plus proche du travail du rêve que de toute construction d'un espace perceptif, matériel, symbolique et axiomatique bien formé et cohérent. L'art travaille par déplacement et condensation, par un dérèglement systématique des deux "axes" langagiers qui organisent le discours: L'art produit, mais par métaphores et metonymies (Gualandi, 2009: 48-49).

En seguida, la visión crítica de Lyotard respecto a Freud y a Lacan, a propósito del trabajo del sueño, le permite a Gualandi sintetizar el modelo de Lyotard:

toujours selon Lyotard, le travail onirique suit une dynamique d'un genre different qu'il faut expliquer dans les termes topologiques et énergétiques $d^{\prime}$ une figure-image, d'une figure-forme et d'une figure-matrice. C'est par cette énergétique prédiscursive qu'il faut donc comprendre le travail de l'art (Gualandi, 2009: 49).

Por nuestra parte, podemos definir los componentes de la estética figural con las palabras del mismo Lyotard, quien en el apartado "Connivencias del deseo con lo figural” de Discurso, Figura (1979: 274-282), sintetiza:

La figura-imagen, la que veo en la alucinación y en el sueño, que me viene dada por el cuadro, la película, es un objeto colocado a distancia, tema; pertenece al orden de lo visible: trazado revelador. La figura-forma está presente en lo visible, visible ella misma en rigor aunque en general no vista: es el trazado regulador de André Lhote; la Gestalt de una configuración, la arquitectura de un cuadro, la escenografía de una representación, el encuadre de una fotografía, en suma el esquema. La figura-matriz es invisible por principio, objeto de represión originaria, mezcla inmediata 
de discurso, fantasma "originario". Sin embargo, es figura, no estructura, porque de entrada es violación del orden discursivo, violencia hecha a las transformaciones autorizadas por este orden (Lyotard, 1979: 274).

Más adelante, agrega información para cada uno de los conceptos definidos y los ejemplifica con obras artísticas específicas. Así, respecto a la figuraimagen, agrega: "es la que se da a ver en el escenario onírico. La violencia recae sobre las reglas de formación de la cosa percibida. La figura-imagen desconstruye el precepto, se realiza en un espacio de diferencia. Podemos articularla con precisión: lo que desconstruye es el contorno de la silueta; es la transgresión del trazado revelador" (Lyotard, 1979: 278). Para este concepto, ejemplifica el cuadro "Estudio de desnudo" (1941) de Picasso. En relación a la figura-forma, sintetiza: "es la que sostiene lo visible sin ser vista, su nervadura; pero también podemos hacerla visible. Su relación con el espacio inconsciente viene dada por la transgresión de la forma buena (Gestalt)" (Lyotard, 1979: 278). Aquí ejemplifica con el cuadro "Pintura" (1948) de Paul Jackson Pollock. Por último, se refiere a la figura-matriz: "No sólo no se la ve, sino que además es tan poco visible como legible. No pertenece al espacio plástico, ni tampoco al espacio textual: es la misma diferencia, y como tal no soporta ese mínimo de puesta en oposición exigida por su expresión hablada, o de la puesta en imagen o en forma que supone por su expresión plástica” (Lyotard, 1979: 280). En esta variante de lo figural, Lyotard no presenta un ejemplo específico, aunque páginas más adelante (342) alude a la obra de Paul Klee. En el estudio de Gualandi, es la pulsión de muerte la que se relaciona con la figura-matriz o matriz fantasmática. Así, señala, enviando, además, a otros pasajes de la bibliografía de Lyotard (Des dispositifs pulsionnels (DP), (1980 [1973]):

La structure, affirme Lyotard, est l'oeuvre du principe de plaisir, de cette instance qui préside à la liaison des énergies, tandis que la matrice figurale est ce qui, par déliaison, répétition et déguisement, déplace le fantasme et libère les différences. La pulsion de mort est l'instance qui préside à toute oeuvre de transformation, déguisement, déliaison (DP, 298). La pulsion de mort est l'instance "ouvrante et différenciante", et c'est grâce à elle que l'art es vérité (Gualandi, 2009: 52).

De esta manera, pensamos que tanto en $L D S$ como en $L N N$ se presentan las distintas variantes de la estética figural; especialmente, la figura-matriz, entendida como la pulsión de muerte, lo cual constituiría la evidencia más 
concreta de la profunda vinculación de los proyectos de Juan Luis Martínez y de Roberto Bolaño, dos brillantes escritores chilenos presionados por la enfermedad y la muerte.

Además, es posible detectar distintos momentos de la obra bolañeana en que se advierten otros procedimientos comunes entre Bolaño y Martínez que, a la luz de la vinculación descrita, adquieren mayor sentido. Esto sucede, por ejemplo, con la presencia de citas apócrifas en La literatura Nazi en América, lo que hasta el momento ha sido abordado enfatizando la vinculación con Jorge Luis Borges, pero se ha pasado por alto la relación que existe, de manera particular, entre el apartado "Epílogo para monstruos" (Bolaño, 2008 [1996]: 221-240) y "BIBLIOGRAFÍA GENERAL SOBRE LOS GATOS” (Martínez 1977: 77) de $L N N$, en que ambos escritores proponen una lista de libros inexistentes. Asimismo, resulta pertinente agregar que en la obra de Bolaño advertimos una recurrente presencia del nombre y figura del autor de $L N N$, como queda demostrado en el nombre que se le asigna al judicial encargado de investigar y resolver los misterios que rodean a los trágicos crímenes de las mujeres en 2666, Juan de Dios Martínez (Bolaño, 2004: 454 $)^{10}$. Destacamos también la idea de considerar a Juan Luis Martínez como una pequeña brújula perdida en el país, en Estrella distante (Bolaño, 2009 [1996]: 57). Igualmente, Bolaño reconoce, de manera explícita, la vinculación con el autor de $L N N$ cuando destaca a Juan Luis Martínez entre los seis tigres de la poesía chilena, junto a Bertoni, Maquieira, Muñoz, Lira y a, él mismo, en el cuento "Encuentro con Enrique Lihn, que forma parte de Putas asesinas (Bolaño, 2001: 219). Del mismo modo, en $L N N$ vemos: "Dados dos puntos, A y B, SITUADOS A IGUAL DISTANCIA UNO DEL OTRO, ¿cómo hacer para desplazar a B sin que A lo advierta?" (Martínez, 1977: 11). Treinta años más tarde, en el texto "EL INSPECTOR" incluido en La universidad desconocida, leemos: "Tome usted la única ruta, desde el punto A hasta el punto B, y evite perderse en el vacío" (Bolaño, 2007: 171). Por último, en el texto "Unas pocas palabras para Enrique Lihn" que forma parte de Entre paréntesis, Bolaño parafrasea uno de los fragmentos incluidos en las solapas de $L N N$, en su afirmación "La literatura ha estado a la altura de la realidad. La famosa rea, la rea, la rea, la rea-li-dad” (Bolaño, 2008 [2004]: 202).

Podemos concluir que es posible reconocer la inscripción de la obra de Roberto Bolaño en la literatura chilena, al observar que entre ésta y su escri-

${ }^{10}$ Esta vinculación es mencionada en un breve texto que forma parte de un Blog de Internet Lanzallamas. Org titulado "Crímenes sin autor", de Martín Cinzano (2005), como un juego de preguntas sin respuesta, sin profundizar, pero dejando abierta una serie de interrogantes al respecto. 
tura se abre un espacio de diálogo fundamental que se manifiesta a través de la estrecha conexión entre su proyecto literario y el de Juan Luis Martínez, los que comparten una serie de procedimientos y búsquedas comunes, y que pueden ser relacionados desde un soporte teórico específico y mediante el corte estratigráfico más profundo: la poesía.

\section{REFERENCIAS}

Ayala, Matías. 2008. "Notas sobre la poesía de Roberto Bolaño”. En Bolaño salvaje. Edmundo Paz-Soldán y Gustavo Faverón Patriau (eds). Barcelona: Editorial Candaya, pp. 91-101.

Bolaño, Roberto. 2000. Nocturno de Chile. Barcelona: Anagrama. . 2000. Tres. Barcelona: Acantilado. 2001. Putas asesinas. Barcelona: Anagrama. . 2002. Amberes. Barcelona: Anagrama. 2004. 2666. Barcelona: Anagrama. 2007. La universidad desconocida. Barcelona: Anagrama. . 2007. [1998]. Los detectives salvajes. Barcelona: Anagrama. . 2008. [1996] La Literatura Nazi en América. Barcelona: Seix Barral. . 2008. [2004]. Entre paréntesis. Barcelona: Anagrama. 2009. [1996]. Estrella distante. Barcelona: Anagrama.

Bolognese, Chiara. 2009. Pistas de un naufragio. Cartografía de Roberto Bolaño. Santiago: Editorial Margen.

. 2010. "Roberto Bolaño y Raúl Zurita: Referencias cruzadas". En Anales de Literatura Chilena 14, pp. 259-272.

Cinzano, Martín. 2005. "Crímenes sin autor". [En línea] Disponible en http://www.lanzallamas.org/blog/2006/04/crimenes-sin-autor. Consulta: 04.04.2012.

Cussen, Felipe. 2009. "Del pajarístico al lenguaje de los pájaros", en Acta Literaria 39, pp. 91-103.

Espinosa, Patricia. 2003. Territorios en fuga. Estudios críticos sobre la obra de Roberto Bolaño. Santiago: Frasis Editores.

Espinoza Orellana, Manuel. 1998. "La acción innovadora de Juan Luis Martínez", en Revista Espíritu del Valle No 4/5, pp. 63-67.

Fuenzalida, Daniel. 2005. Enrique Lihn: Entrevistas. Santiago de Chile: Juan Carlos Sáez, editor.

Fuguet, Alberto. 1997. "21 notas sobre la nueva narrativa". En Olivares, Carlos. Nueva narrativa chilena. Santiago: LOM, pp. 119-122. 
González Echevarría, Roberto. 2010. "Nocturno de Chile y el Canon”, en Acta Literaria 41, pp.117-128.

Gualandi, Alberto. 2009. Lyotard. París: Perrin.

Herrera, Juan. 2007. “La nueva novela de Juan Luis Martínez: Poesía protohipertextual en el contexto de la videósfera”, en Acta Literaria 35, pp. 9-27.

Houellebecq, Michel. 2011. Intervenciones. Barcelona: Anagrama.

Lastra, Pedro. 2011. "Marginalidad y poesía en Hispanoamérica”. En Chile mira a sus poetas. Estudios y Creaciones. Paula Miranda Herrera y Carmen Luz Fuentes-Vásquez (eds.). Facultad de Letras de la PUC. Santiago: Editorial Pfeiffer, pp. 27-39.

Lihn, Enrique. 1985. "Juan Luis Martínez, La nueva novela”, en El espiritu del Valle 1 (diciembre), pp. 89-91. Compilada también en El circo en llamas (1997: 177-180).

1997. El circo en llamas. Santiago de Chile: LOM ediciones.

Lihn, Enrique / Lastra, Pedro. 1987. Señales de ruta de Juan Luis Martínez. Chile: Ediciones Archivo.

Lyotard, J. F. 1979. Discurso, Figura. Barcelona: Editorial Gustavo Gili. 1980 [1973] Des dispositifs pulsionnels. París: Christian Bourgois Edit.

2008. La posmodernidad (explicada a los niños). Barcelona: Gedisa.

Madariaga, Montserrat. 2010. Bolaño Infra. 1975-1977. Los años que inspiraron Los detectives salvajes. Santiago: RIL editores.

Manzoni, Celina. 2006. Roberto Bolaño. La escritura como tauromaquia. Buenos Aires: Corregidor.

Marks, Camilo. 1997. "El nombre no es lo de menos”. En Olivares, Carlos. Nueva narrativa chilena. Santiago: LOM, pp.15-20.

. 2003. "Roberto Bolaño, el esplendor narrativo finisecular", en Territorios en fuga. Santiago: Frasis Editores, pp. 123-140.

. 2010. Canon. Cenizas y diamantes de la narrativa chilena. Santiago de Chile: Random House Mondadori.

Marras, Sergio. 2011. El héroe improbable (como Arturo Belano siempre quiso ser Benno von Archimboldi). Santiago de Chile: RIL Editores.

Martínez, Juan Luis. 1977. La nueva novela. Santiago: Ediciones Archivo.

Merino, Roberto. 1988. "Juan Luis Martínez: La nueva novela. La memoria secreta", en Revista Número Quebrado 1, septiembre-diciembre, pp. 2327.

Monarca, Patricia. 1998. Juan Luis Martínez. El juego de las contradicciones. Santiago de Chile: RIL Editores. 
2011. Mutación Epistémica. (Una lectura de La Nueva Novela desde la interdisciplinariedad y la complejidad del saber). Dudweiler Landstr. 99, 66123 Saarbrücken, Alemania: Editorial Académica Española.

Olivárez, Carlos. 1997. Nueva narrativa chilena. Santiago: LOM.

Parra, Nicanor. 2006. Obras completas \& algo +. Barcelona: Galaxia Gutemberg.

Paz-Soldán, Edmundo y Gustavo Faverón Patriau. 2008. Bolaño salvaje. Barcelona: Editorial Candaya.

Poblete Alday, Patricia. 2010. Bolaño otra vuelta de tuerca. Santiago de Chile: Universidad Academia de Humanismo Cristiano.

Valdivieso, Jaime. 1996. "La subversión lógica de Juan Luis", en "Artes y Letras" de El Mercurio, 22 de diciembre, p. E4.

Valente, Ignacio. 2010. "200 años de Literatura chilena", en "Artes y Letras" de El Mercurio, 19 de septiembre, p. E2.

Zambra, Alejandro. 2002. "La montaña rusa”. En Roberto Bolaño. La escritura como tauromaquia. Buenos Aires: Corregidor, pp. 185-188. . 2010. No leer. Crónicas y ensayos sobre literatura. Santiago de Chile: Ediciones Universidad Diego Portales. 
